\title{
Assessment Of Development Plan And Protection For Birhor Community Of Duru Kasmar Village, Mandu, Jharkhand
}

\author{
${ }^{1}$ Jai Kumar , ${ }^{2}$ Rajni Kant Kumar \\ ${ }^{I}$ Department of Remote Sensing, Birla Institute of Technology Ranchi, India \\ ${ }^{2}$ Department of Veterinary medicine, Ranchi veterinary collage, Birsa Agricultural University Ranchi,India
}

\begin{abstract}
- birhor are tribal/adivasi forest people, traditionally nomadic, living primarily in the indian state of jharkhand. birhors are certain tribal communities who have declining or stagnant population, low level of literacy, and are economically backward. the overall objective of the cluster development model is to develop the selected ptg cluster in an integrated manner with development and financial services focusing on social, economic, infrastructure and human aspects of development. rural appraisal exercise (resource and social map, seasonality, chapati diagram, observation), household survey. the sustainable structure will be established with the policy of working pro-people. Cluster Based Model" which can be up scaled and replicated in all such PTG Cluster in different parts of the country.
\end{abstract}

Keyword- birhor, CDM, development plan , protection.,

\section{INTRODUCTION}

Government of India has taken to be 75 tribes across the country as low in development groups. Among them, Birhor is one of the low in development group groups who a bit their place of birth in jharkhand and live for ages in different parts of the state. Birhor in jharkhand be part of to the Proto-Australoid amount of goods; through language, they make first from the Austro-Asiatic group. The word "Birhor" is formed from by putting together 2 Mundari words: "Bir" means Forest while hor means man. Thus Birhor means Forest man or people living in the Forest. It is interesting to note that the Birhor group of jharkhand take into account themselves as the ones coming after of the Sun. It is had belief that the Birhors are related to the kharwar group, also said to have went down from the Sun. In jharkhand the Birhor group is separated into 2 Major sub-tribes, namely Jaghis Birhor and Uthalu Birhor. These tribes in jharkhand make picture of a separate good example of society-business way of living.

Jharkhand is a state in Eastern India. It was carved out of the southern part of Bihar on November 15, 2000. The state has an area of 79,710 km. Jharkhand has high proportion of Scheduled Tribe population which is about 26.3 percent against an all India average of 8 percent, and a high percentage of area under forest cover which is about 29 percent against the Indian average of 23 percent. Among the 32 tribes in Jharkhand, nine tribes have been classified as PTG (Primitive Tribe Groups). They are - Asur, Birhor, Birajia, Korwa, Parahiya (Baiga), Sabar, Mal Pahariya and Souriya Pahariya and Bil Kahria. In Jharkhand, the PTG population is just 2.23 lakh as per 2011 Census. They are primarily hunters and gatherers. The livelihood options of these primitive tribal groups are broadly classified as Agriculture, Forestry, Handicrafts and Handlooms.

\section{BIRHOR}

BIRHOR are tribal/Adivasi forest people, traditionally nomadic, living primarily in the Indian state of Jharkhand. Birhors is one of the PTG living in the districts of Hazaribagh, Giridih, Ranchi, Lohardaga, Palamu, Garhwa, Dhanbad, and Singhbhum in Jharkhand State. Most of these groups are small in number, have not attained any significant level of social and economic progress and generally inhabit remote localities having poor infrastructure and administrative support. BIRHORs are certain tribal communities who have declining or stagnant population, low level of literacy, and are economically backward.

Therefore, they become the most vulnerable sections among the scheduled tribes and thus priority is required to design and strategize a long term "assessment of development plan and protection" for their protection, checking the declining trend of their population and their development. Since BIRHOR constitute the most vulnerable section among tribals and inhabit isolated, remote and difficult areas in small and scattered hamlets/habitats, the development plan should focus on their socio-economic development in a holistic manner by adopting .Cluster Development Model, intervening in all spheres of their social and economic life. 


\subsection{Cluster Development Model (CDM)}

CDM concept could address these challenges of BIRHOR comprehensively. It can address resource deficits in each of socio economic sectors, with adequate focus on the special needs of each family of the PTG Cluster. The Overall Objective of the Cluster Development Model is to develop the selected PTG Cluster in an integrated manner with development and financial services focusing on social, economic, infrastructure and human aspects of development.

\section{II.}

STUDY AREA PROFILE: DURU KASMAR VILLAGE

Duru Kasmar Village is located in Basantpur Panchayat of Mandu Block of Ramgarh District. It is situated $17 \mathrm{~km}$ away from sub-district headquarter Mandu and 40km away from district headquarter Ramgarh. As per 2011 Census, Duru Kasmar Village has a total population of 1630, from 340 households, including 55 families of Birhor Community residing in a separate hamlet within Duru Kasmar Village called "Duru Kasmar Birhor Tola (DKBT"). DKBT is situated at about $13 \mathrm{kms}$ on Kuju -Ghatotand Highway. The DKBT shares it boundary with Basantpur village in North, Panji in South, Ghato Kedla Highway in East and Duru Kasmar village in West.

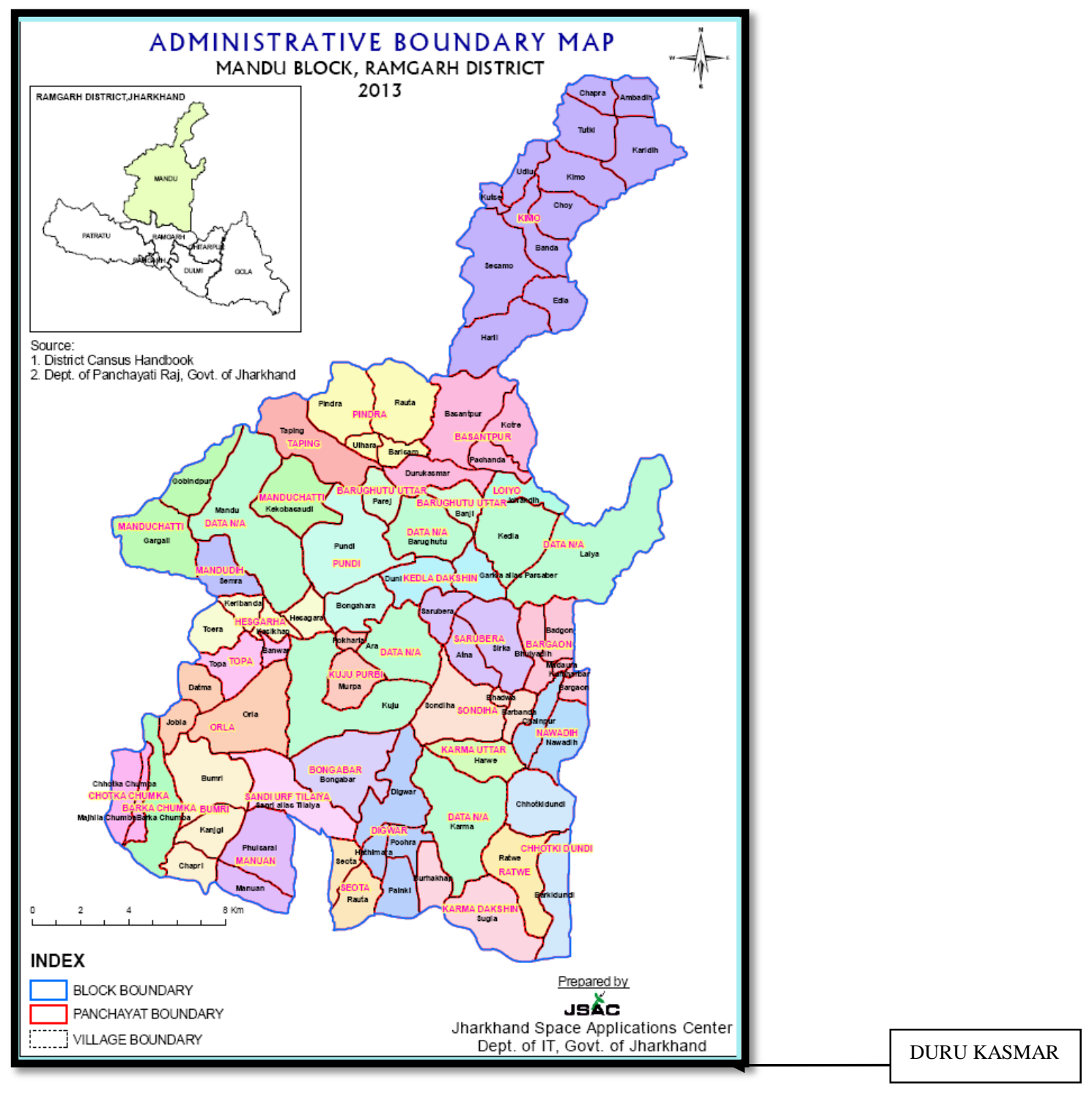


Village DKBT comes under Basant Pur Panchayat, other villages within Basantpur Panchayat are Kotre, Pachanda, with head quarter of GP at Basantpur. Since Birhors comes under PTG few social welfare and development work has been undertaken by the government and development agencies. The major work taken up is through Government and CSR activity of Tata Steel Rural Development Society (TSRDS). Benefit under social scheme such as BPL card, $35 \mathrm{~kg}$ Rice from PDS, Rs 600 pension to families, are bring provided through government department. TSRDS has taken up few development initiatives in the Birhor Tola in recent past such as a well for drinking water (Dry up in summer season, open well poor water quality ), A boring well with storage tank (Malfunctioned), Solar lights (Light panel are missing), A electricity transformer has been set (Still few houses doesn't have proper electric supply ) and Community hall (Closed down, no use).

At present Village has one Aaganwadi center, where around 60 children upto the age of 0-4 are enrolled. There is no school, no health sub centre, no transport facilities to go to the nearby market (Panji Village $5 \mathrm{~km}$ ), and GhatoTand $10 \mathrm{Kms}$. Village has no access to education facilities, proper health facilities, Transport facilities, have no drainage system, and faces serious water borne disease problems during rainy season and drinking water facilities during summer season.

\begin{tabular}{|l|l|}
\hline Name Of Village & Duru Kasmar Birhor Tola \\
\hline Total population & 207 \\
\hline Male & 112 \\
\hline Female & 95 \\
\hline Total HH & 55 \\
\hline
\end{tabular}

All the BIRHOR families live according to their traditional primitive lifestyle and are deprived of basic amenities hence, suffer from extreme poverty, starvation, children are malnourished, anaemic adolescent girls and women, more than $90 \%$ Birhors males are addicted to Alcoholism, have illiteracy and poor health.

The prime source of income of the community is through rope making, and selling Timber collected from Nearby forest. On an average annual income of a Birhor Family is Rs 15000 only, which forces them to live under harsh conditions. Under social welfare scheme lands are allotted to Birhor families, which can be used for agriculture production and income generation activity. Due to lack of better livelihood options, literacy, education Birhors are deprived of their basic rights and unable to express their feeling before society.

\section{The social assessment study brought out the following:}

Birhor are socially and economically disadvantaged in comparison to others.Birhor Community needs special developmental needs in terms of access to services and facilities compared to other backward groups in a "assessment of development plan and protection" having Cluster Development Approach.They are perpetually excluded from the decision making, are forced to remain as needy dependent on grants and free aids, rather than having skill based empowerment process.

\section{SOME MAJOR FINDINGS.}

A Participatory Rural Appraisal exercise (Resource and Social Map, Seasonality, Chapati Diagram, observation), Household Survey including interview with few key persons were conducted for situation analysis and designing a community specific, need based plan for Birhors of Duru Kasmar Birhor Tola.Habitants: Birhor Communities resides in a separate hamlet within the Duru Kasmar Village. All the 55 Birhors families are settled in this hamlet. They have kuccha houses, having no toilet facilities and no drainage system in the village. Since all are under BPL category, they are allotted Indira Awas and Birsa Awas through government of Jharkhand, which is under construction at few household. Though they have an elected Panchayat representative (Not from Birhor Community), birhor community have no interaction with the ward Parshad.

Literacy: Community has poor literacy rate in both male and females, as community has no access to schools other than Aagnawadi. Community has no access to formal education system as there is no school in the village.

Poverty: All families come under BPL and are living under very harsh conditions. Since they are mostly dependent on rope making, collecting woods from forest, and daily wage labour as their source of income, which is very less to survive and grow.

Inaccessibility: Though the Village is located near to the Highway, no local public or private transport are accessible to these community. They generally walk to nearby market (Panji- $5 \mathrm{~km}$ ), or Ghatotand (10 Km). In emergency cases at nights or crisis situation (Delivery cases, snake bites), things become very critical for community even causing danger for life. 
Availability of Land \& Livestock Resources: Most of the household have settled in the area since decades, with no proper registration of land to these families. Now these families are allotted land ranging from 3 dismil to 25 dismil within same locality by government of Jharkhand. These lands can be used for agriculture purpose as income generation activity. Out of 55 families only 8 family have few livestock. There is great potential for Livestock rearing for income generation activity especially Gottary \& Piggery.

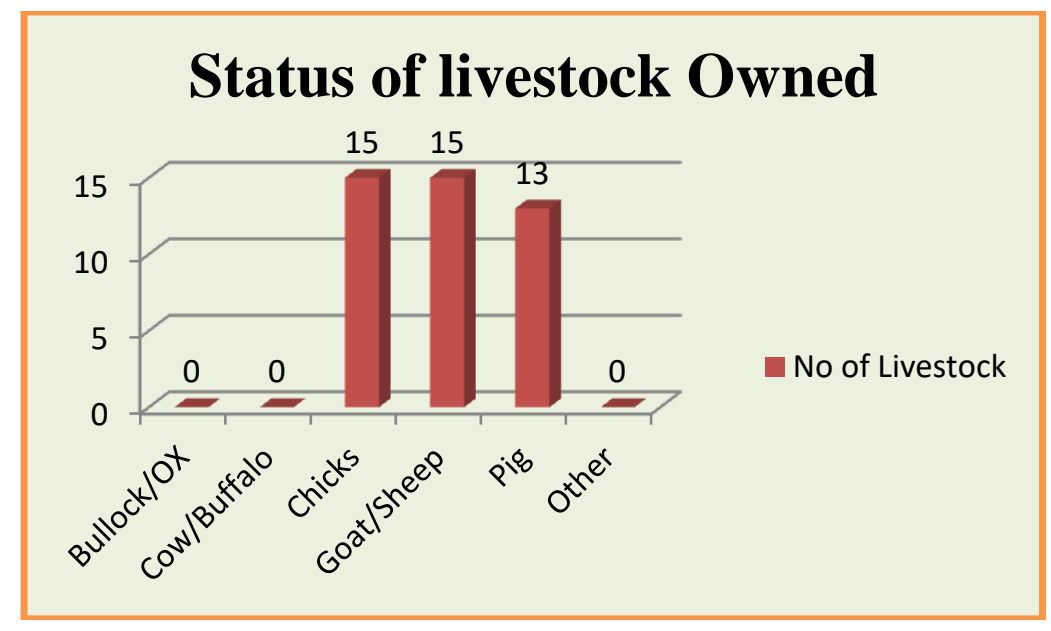

Average Annual Income vs Expenditure

Water \& Samitation: There is no govt. water supply in the hamlet. All the handpumps dug under government scheme are malfunctioned. Community is dependent on the private water source (Well) dug under CSR activity of TATA Steel. A bore well was also provided by TSRDS, which is not functioning. This well is the only source of drinking water for the community, which dries up in the month of summer. During summer season they have to fetch water from Chitua river, at a distance of $8 \mathrm{kms}$. For other domestic purpose they use the water of 3 small ponds of the village. Two of them dries up in summer. During rainy seasons, under lack of proper drainage system, communities get affected of water borne diseases. Families are living under unhygienic conditions, where children are exposed to diseases. Though toilets are newly constructed at household level, the community is raising doubt over the usage of toilets under shortage of water supply in the area. A Jal Minar with piped water supply system to the village could be the proposed solution for the acute drinking water problem of the area.

Source of HH Annual Income and Savings and Expenditure: Out of 55 families Major source of income is through rope making (10 Families), and selling forest wood (33 Families) in the nearby market, where the entire annual income is spent on food and clothes, leaving no savings for other basic amenities.
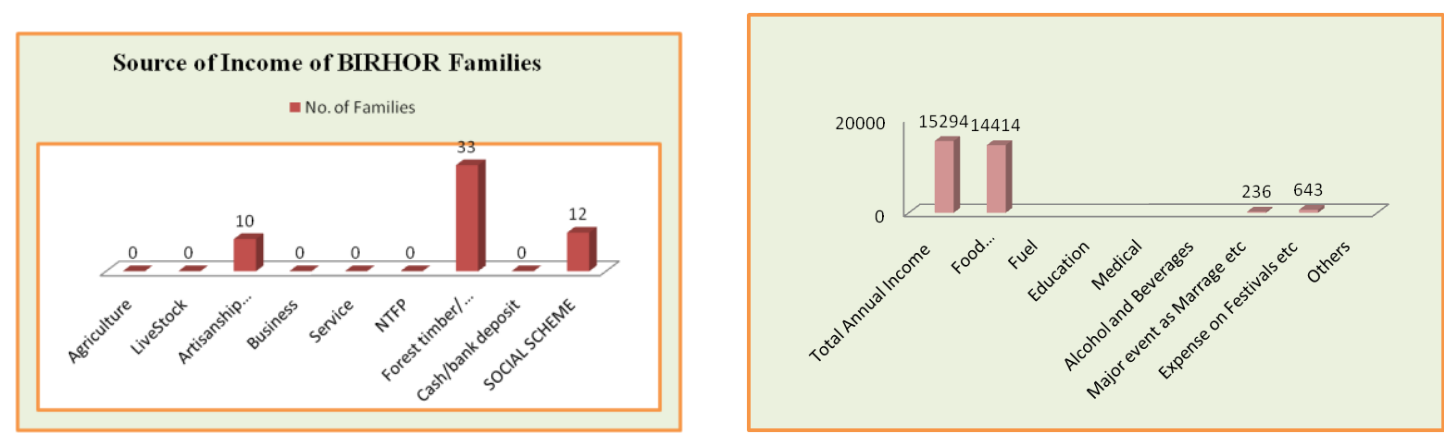

Access to Social Entitlement:

Almost all the Families have BPL Card, access to $35 \mathrm{KG}$ rice distributed through PDS system, houses under Indira/ Birsa Awas Scheme and few getting benefits of Rs 600 per month under Pension scheme. Apart from basic schemes they need to be provided technical training with financial assistance to get jobs/ to be self employed to get empowered, reducing their dependence on grant and aids from government or development agencies. 


\section{ISSUES FOR CONSIDERATION UNDER ASSESSMENT OF DEVELOPMENT PLAN AND PROTECTION.}

Birhor community residing in the area are unaware of their social entitlements, and doesn't have the voice heard in any platform, The priority task is to organize them in a coordinated way with specific objectives. Promotion of Women SHG and Men JLG need to be prioritized for inculcating the practice of savings, formation \& strengthening local social institutions. All the birhor families are living under extreme poverty, their daily earning totally gets spent on availing food for their families. They are forced to get trapped in vicious cycle of poverty, which can only be broken of each household gets some skill training and move to some other better income generation activity. This transition period (May be 12 to 18 months) is very crucial for these families to move out of their daily routine and adapt to new skills. Each Birhor Family needs to be supported with every household necessity (Food, Clothes, medicine, utensils, household basic materials etc) within this transition phase so that they are encouraged and motivated to adopt to new skills and new routine of daily life.

Birhors community need to be prepared to reduce their dependency on government supplied AID, materials. They need to be engaged in livelihood activities such as piggery, goatery, kitchen gardening, driving, Handicrafts through skill based training and financial assistance. Since all Birhors are poor and mostly addicted to alcoholism; all the livelihood activities promoted in the area are shut down in between due to in disciplined behaviour of the community. Specific Skill based training with financial support need to be introduced to each household of community under strict supervision. Since most men and few women are addicted to alcoholism, they need to be kept under direct supervision. All income generation activities need to specific and should take Revenue based Incentive livelihood promotion approach, where they will be motivated to adapt to the new working conditions, where they will get the cash incentive in achieving the different stages of respective livelihood activity.

Birhor communities are closer to Nature and forest, yet they are far from practicing agriculture for income generation activity. The new allotted lands (ranging from 3 dismil to 20 dismil) to all Birhor Families should be used for promoting Kitchen Gardening. Irrigation facilities need to be ensured from the near by Ponds and Rivers. (Exiting Ponds shall be deepened and new structures can be created, as per need). All the Birhor families have the potential for doing kitchen gardening in at least 3 dismil of land

Proper drinking water supply system needs to be installed, in the area by making bore well in the west side of the village having higher water table. A Jal Minar need to be constructed to store the extacted ground water and through gravity flow, drinking water shall be supplied to the village through a laying pipe line with 6 different outlets covering all 55 household of the Hamlet. (The existing malfunctioned bore well of lower capacity need to be immediately repaired for alternate source of water supply ).

Village based BIRHOR UPLIFTMENT RESOURCE CENTER need to established which will have all the basic data of the all BIRHOR families, will have a facilitation center including recreational activities, Alcohol de addiction center, Information cum facilitation center for availing all the social schemes, a bridge schools for dropout children, and a vocational training centers. An under constructed 2 storey building within the village can be used for developing this Centre.BIRHOR community is one of the PTG which is a the verge of extinction, and that could only be stopped and reversed if the younger generation are protected and are healthy. Birhor Tola does'nt have any health center to provide health services. Almost all the children are malnourished and women are anemic, which is taken care by the village aanganwadi, without having any equipments and facilities. (A model Aanganwadi center as per ICDS guideline and a model sub center as per IPHS guideline need to be established immediately). Investing on the children can only be the solution for avoiding the BIRHORS from getting extinct, and grow in future. (A community hall constructed through TSRDS can be used for establishing the Health Sub Center, where as the existing Aagnawadi need to be modified.)

BIRHORS traditional, religious, and cultural rights need to be protected, and should be promoted in their true sense, through various IEC activities and exposures.

Village Infrastructure such as installing, Village light, electricity supply to each household, proper roads construction, constructing drainage system \& waste dumping sites, supply of unnat chulah etc need to be executed.Convergence of all government schemes and plans is required to build up a "Inter Department al collaborative action plan" for the upliftment for BIRHOR community and their Hamlet.

\section{v. CONCLUSION}

Intervention Strategy

A. Sustainable: The implementation strategy will ensure that the evolution of the "Integrated Protection Cum Development Plan" in a Cluster Development Model approach is sustainable in itself. This could be 
ensured only when the local community is capacitated and active enough to take the initiations. This will be ensured through:

- Formation and Strengthening of Local Institutions

- Handholding Support through the Transition Period.

- Ensuring Access to Social entitlements and rights

- Empowering community through Livelihood promotion activities.

- Promotion of Moral \& Ethics, protecting cultural and traditional rights of BIRHORs.

B. Convergence with other departments: Through Developing Inter Departmental Collaborative Action Plan.

C. Pro People: The sustainable structure will be established with the policy of working pro-people. But the ecology, at the same time, will be considered with utmost importance. A synergy between the short term benefits and long term sustainability plan will be ensured.

D. Maximum focus to strengthen Individual, Family \& Institutions: Different social institutions will be developed and strengthened to ensure the sustainability of the growth of the village.

E. Participatory Implementation: All the implementation activities will be carried out with the participation of the local community. Handholding will be done to strengthen the community to take care of the activities in long period of time after phasing out of the proposed project. Indicator based monitoring to be practiced including Social Audit.

F. Expandable and Replicable: The created impact will result in setting up a "Cluster Based Model" which can be up scaled and replicated in all such PTG Cluster in different parts of the country.

\section{VI . ACKNOWLEDGEMENTS}

I would like to thank my father and mother, Shri Khelanand Raut, dugha coal washery, for contributing a lot of effort in providing me with resources, study materials and reading manuscripts and for devoting his valuable time and always being a constant source of advice and inspiration without which this work wouldn't have been possible.

\section{REFERENCE}

[1] nivedita mitra and subrata chakrabarti ECONOMIC STRUCTURE OFBIRHORS IN PURULIADISTRICT, WESTBENGAL international multidisciplinary research journal $\mathrm{v}$ ol 2 issue 2 aug 2014

[2] Jitendra Kumar PremiBirhor: The Inconsequential Extraordinary Primitive Tribal Group (PTG) of India,Research J. Humanities and Social Sciences 2014; 5(4) 366-369

[3] Amia Ekka, ,Neelam Sanjeev Ekka Traditional Health Care in Birhor Tribes of Chhattisgarh Online International Interdisciplinary Research Journal, \{Bi-Monthly\}, ISSN2249-9598, Volume-III, Issue-VI, Nov-Dec2013

[4] Somnath Mukherjee, Bankura, Status of Female Education among Santal, Kheria Sabar and Birhor Tribal Communities of Puruliya District, West Bengal, India Trans. Inst. Indian Geographers, Vol. 36, No. 2, 2014

[5] Ranjana Agarwal Manish Pruthi , Pawan Lodhi \& Pallavi Kumar SUSTAINABLE LIVELIHOOD OPTIONS FOR PRIMITIVE TRIBAL GROUPS IN JHARKHAND: CSR INITIATIVES BY TATA STEEL AIMA Journal of Management \& Research, February 2013, Volume 7, Issue 1/4, ISSN 0974 497

[6] Sagari Chaudhury,Chowdhury Habibur Rahaman and H. Singh Some ethnozoological uses of Birhor tribe of West Bengal, India, J. Traditional and Folk PracticesVol. 02, 03, 04(1); 2016 